\title{
Development and implementation of the National Science and Technology Policy in Sri Lanka
}

Science, technology and research based innovations are increasingly recognised as the determinants of national development and growth, particularly in developing countries. It is therefore essential for every developing country to formulate and implement a comprehensive and strong national science and technology policy (STP) to stimulate sustainable development by appropriate use of S\&T resources.

The earliest attempt to formulate a S\&T policy in Sri Lanka was during the period $1950-1960$ by the Ceylon Association for the Advancement of Science, the predecessor to the Sri Lanka Association for the Advancement of Science (SLAAS). In 1978, a 7-point S\&T policy statement was developed by the National Science Council (NSC) in association with the SLAAS. In 1986, a Presidential Task Force was appointed with the mandate to look into all aspects of S\&T and in particular the implementation of the 7-point policy objectives developed by the NSC. In 1991, this Task Force submitted a report recommending several projects and programmes with a view to achieve the 7-point policy objectives. Based on this report, a S\&T Development Bill was presented to the Parliament in 1994 and this was unanimously passed as the Science and Technology Development Act No. 11 of 1994. This Act brought together the S\&T institutions under the purview of a Ministry of Science and Technology. The Act also provided for the establishment of a National Science and Technology Commission (NASTEC). This Commission was mandated to develop policies and plans for the advancement of S\&T and the application of S\&T for national development.

In 1996, prior to the establishment of NASTEC, the National Science Foundation (NSF), the successor to the NSC and the Natural Resources, Energy and Science Authority (NARESA), developed ten policy elements. In 2007 the NASTEC, which was established in 1998, initiated extensive consultations with the relevant stakeholders to develop a new S\&T policy. The new policy was approved by the Cabinet of Ministers in 2009 as the National Science and Technology Policy (NSTP). This policy dealt with two major aspects - the development of S\&T in the country and the application of S\&T for national development. The NSTP recommended 10 policy objectives and relevant strategies for realisation of the objectives. The responsibility of implementing the NSTP was vested with the Ministry of Technology and Research (successor to the Ministry of Science and Technology) as per the NSTP. Thus the Ministry dealing with Science, Technology and Research was identified as the executive arm of the NSTP.

Recognising the cross-cutting nature of S\&T and the mandates of various other ministries, the NSTP recommended the establishment of an Inter-Ministerial Committee (IMC) on S\&T, chaired by the Head of State with the Minister-in-charge of S\&T as the Vice-Chairperson. This committee was envisaged as the body, which will co-ordinate the S\&T policy implementation through the functioning of the different ministries. The committee was also expected to set funding priorities, decide on major research and development (R\&D) initiatives and monitor the implementation of the NSTP. The recommendation regarding the establishment of the IMC was not implemented. If the recommended IMC was appointed, it would have ensured the alignment of the action plans of the S\&T institutions under different ministries with the NSTP and would have coordinated their activities avoiding any overlap.

In 2009, the NASTEC developed a five year (2011 - 2016) action plan for implementation of the NSTP, after extensive consultations with all S\&T institutions, scientists, technologists, academic community and administrators. This plan was formulated taking into consideration the mandates of the S\&T institutions coming under the purview of all ministries. This action plan was also not implemented. 
Subsequently, the S\&T Ministry, recognising the importance of S\&T and innovations, developed a Science, Technology and Innovation Strategy 2011 - 2015 (STIS) with a prioritised course of action based on the NSTP. This strategic plan had four goals and a total of eight objectives. All these objectives are in agreement either totally or partly with the NSTP and therefore the STIS could be considered as a mechanism to implement the NSTP. The implementation of the STIS 2011 - 2015 was vested with a newly established Coordinating Secretariat for Science, Technology and Innovation (COSTI) set up with considerable investment by the State.

In 2014, the Ministry of Technology and Research, working in close collaboration with NASTEC, formulated a R\&D Investment Framework 2015 - 2020 to align the activities of the S\&T institutions towards national development and a knowledge economy driven by science, technology and innovation. This plan identified ten (10) possible interventions for bridging the gap between research and development in 10 focus areas important for national development. The identified focus areas and interventions of this investment plan have some similarities with the strategies of the NSTP.

The Minister of Finance, in the Budget proposals for 2016, stated "Our investment in science, technology and innovation has failed to keep up with the growth in GDP. Its impact is evident in the low percentage of high tech value addition to our manufactured exports $(0.9 \%)$, poor contribution of patents and research based services and industries to our economy. This has to change rapidly if our economy is to be led by innovation. We expect high tech manufactured exports constitute at least $10 \%$ of our exports by 2020". The Minister has further said
"I propose to set up a National Innovation Centre (NIC) in the Ministry of Science, Technology and Research, which will manage the Innovation Accelerator Fund set up as a revolving fund. It is proposed to allocate Rs. 100 million as seed capital to this Centre while another Rs. 3,000 million will also be provided within a period of 3 years".

This is a most encouraging and significant development towards the promotion of ST\&I activities, which can also be seen as the implementation of the second policy objective and the $1^{\text {st }}$ strategy of the NSTP, which recommended the progressive increase of investment on S\&T up to $1.5 \%$ of GDP by the year 2016. Inadequate investment for ST\&I was one of the impediments for implementing the NSTP. The allocation of funds for specific ST\&I activities in the 2016 Budget removes this impediment to some extent. It is now the responsibility of all stakeholders including the line Ministry for Science, Technology and Research, S\&T institutions and most importantly the scientists and technologists along with S\&T administrators as well as researchers in S\&T to make use of the allocation for ST\&I with maximum determination for the development of the country.

A change of mindset on the part of science and technology researchers is of prime importance. It is the scientists and technologists who can, with their research based innovations that can give the leadership to increase the number of patents and high-tech value added manufactured exports. To achieve this, the scientists and technologists must work together with the industrial sector in public-private partnerships that will accelerate the commercialisation of research findings resulting in economic development of the country.

Nalini Ratnasiri 